\title{
The profile of people reporting with low back pain to a resource poor clinic in Cape Town
}

\begin{abstract}
In order to provide targeted information regarding understanding and management of low back pain (LBP), it is necessary to understand the life situation of patients. The objective of this study was to develop a profile of patients with LBP seeking care in an under-resourced area of Cape Town.

The subjects were all patients attending a community health centre with a primary diagnosis of LBP. A self-designed questionnaire was used to gather relevant information such as BMI, smoking, physical activities at home and work and potentially stressful life events. Questions about perceptions of LBP, the role of health personnel, income and employment were included. Subjects could also identify which information they would like to be given by their health care providers.

Fifty subjects were interviewed, 74\% were female. The mean ages were 50.7 years (SD 14.0) and 54.1 years (SD 15.1) for males and females respectively. There was a high prevalence of smoking and obesity, low levels of education, and many reported high stress levels. There were a high percentage of manual workers and the nature of their activities could put them at risk for development and exacerbation of LBP. Few people knew what to expect with regard to the likely outcome of their pain and the majority identified the need for communication about the duration, prognosis, implications and management of LBP. Conclusion: A profile developed of the typical LBP patient in this community provided valuable information, which can be utilized to develop appropriate intervention strategies.
\end{abstract}

\section{KEYWORDS: PROFILE, LOW BACK PAIN, LACK OF KNOWLEDGE, STRESS, COMMUNICATION, INFORMATION.}

\section{Introduction}

Low back pain (LBP) is a significant problem in many countries (Goubert et al., 2004; Jin et al., 2004; Walker et al., 2004), in addition to suffering and functional limitation, it places an economic burden on both the individual and the state (Korthals-de Bos et al., 2004; Luo et al., 2004; Lutz et al., 2003; Woolf and Pfleger, 2003). Lifetime incidences can be as high as $80 \%$ (Santos-Eggimann et al., 2000) and in many countries a large percentage of the health budget is utilized on managing LBP (SantosEggimann et al., 2000). Although there appears to be little information available

\section{Correspondence to:}

Deborah L. Yates

Residence Les Balisiers,

Porte B.,

Rue des Fréres Gay,

Toulon 83000.

France

Email: hardy.debb@gmail.com on the community prevalence of low back pain in South Africa, a recent study in Cape Town found that $28 \%$ of the 1005 community clinic attendees interviewed reported having had spinal pain within the previous three months (Parker and Jelsma, 2010). A review of studies on LBP completed in Africa, indicates high levels of prevalence comparable to those found in developed countries. (Louw et al., 2007). Successful and costeffective methods of managing LBP need to be identified and utilized to reduce the burden on the individuals and on the economy.

Many possible causes of LBP have been considered in different studies. It is perhaps useful to briefly look at a cross section of these possibilities in order to try to begin to have some concept of the scope of the problem as it may exist in South Africa, however it must be kept in mind that if LBP is a problem in South Africa it cannot be presumed that the causes are similar to those established in other countries. Similarly treatments, which have been found to be effective in other countries, may not be effective in South Africa or these treatments may not be cost-effective or suitable in the South African context.

The genetics of the individual, the biology and biomechanical relations of the spine and its components that allow us to be supported in all the activities of daily life in work and leisure have apparently shown specific factors that may contribute to LBP. The intervertebral disc, its responses to the passage of time and specific activities of daily life and its contribution to LBP has been the subject of much research. Other topics considered include age, gender, obesity, pregnancy, trauma, smoking, and the presence of other diseases, culture, education, economic status, and stress. Occupation, occupational postures, leisure activities and psychosocial aspects have all been considered in relation to LBP. If all these things can contribute towards LBP, an understanding of these aspects in a particular community 
may help towards an understanding of any possible presence of LBP in that community.

One author has classified the causes of LBP into three categories: biologic, physical and psychosocial and indicates that each of these have their influence (George 2002). From a review of some of the more recent literature on LBP, it seems that both intrinsic and extrinsic physical and psychosocial factors such as those listed above may be relevant. However it appears that these factors are inter-related making it difficult to specifically categorize any single cause. It is therefore not surprising that it might be difficult to give a specific diagnosis of the cause of LBP in an individual or group of people or to produce evidence of a single successful treatment approach.

The most effective treatment for low back pain has not yet being identified (Lutz et al., 2003). Providing education, information and advice have been found to be useful (Burton et al., 1999; Cherkin et al., 1996; Little et al., 2001; Rivero-Arias et al., 2006; Schenk et al., 1996) and it has been recommended that these should be prioritized as intervention strategies as they are simple and cost-effective. The provision of educational material has been found to be most effective when it is related to the expressed needs of the patient (Liddle et al., 2004; Moffett et al., 1999; Roberts et al., 2002a). It is therefore possible that a tailor made information leaflet, which speaks to the specific needs of the patients depending on their possible risk factors, might result in more effective management of LBP.

A 240 page evidence based document issued by the Royal College of General Practitioners in Great Britain in 2009 on the early management of non-specific low back pain, suggests that patients are: provided with advice and information to promote self management of their low back pain, encouraged to be physically active and provided with an educational component together with other interventions (The Royal College of General Practioners, 2009).

This study, firstly, aimed to explore the lifestyle of people from a resource poor community in South Africa presenting with a complaint of acute LBP (ALBP) and, secondly, to understand their needs regarding LBP intervention. Specific objectives included collecting demographic data; exploration of possible contributing factors, evaluation of levels of understanding regarding ALBP and subjects' needs in relation to information about ALBP.

The study took place in a resource poor area of Cape Town, with a diverse spread of occupational categories - most of which involved in physical work of some kind. Many women were domestic workers while others worked at a large bakery and reported heavy lifting of bags of flour, buckets of cream and cake mixture. Men and women were employed at a gemstone factory and described lifting heavy stones for sorting and cutting. In addition, some men from this historically fishing seaside community were fishermen. "Trek" (Afrikaans for pull) fishing - where nets cast to sea by boat are manually pulled to shore by fishermen on the beach is a common fishing practice in this area.

Subjects used in this study were visiting a local government health clinic, to see the medical practitioner for an episode of acute low back pain (ALBP). This clinic provides medical care for a community of 21,000 people (Department of Health, 2006) of mixed ethnicity. The routine practice of the doctor for a normal complaint of LBP was to prescribe time off work if necessary, prescribe antiinflammatory medication and give out a leaflet on LBP produced by a pharmaceutical company. According to the practitioner, this was all that was possible during the limited 10 minutes available for each consultation.

\section{Methods}

A descriptive cross-sectional analytical study design was utilised. Subjects were recruited from all those attending the clinic with a primary diagnosis of LBP during a 7-month period in 2006. Inclusion criteria required written consent; aged 18 to 80 years; consultation for a new episode of ALBP (pain of recent onset originating from the back and defined in an area bounded by the $12^{\text {th }}$ thoracic vertebra and $12^{\text {th }}$ ribs superiorly, the gluteal folds, inferiorly, and the contours of the trunk laterally) and an ability to understand English. The exclusion criteria, screened by the doctor, were indicators of serious pathology.

A 116 question Lifestyle Questionnaire was developed based on factors identified in the literature as having an impact on ALBP and was modelled on the Back Home Trial (Roberts et al., 2002b). The first half of the questionnaire focused on demographic and contributing factors such as gender, age, education level, BMI, smoking, physical activities, potentially stressful life events. The second part of the questionnaire focused on perceptions about LBP, the role of the doctor and physiotherapist, income and employment. The questionnaire also allowed subjects to identify what they felt would be useful to know in order to manage their LBP such as information about anatomy of the spine, how to move, sleep and manage pain during daily tasks.

TheMedicalResearchEthicsCommittee of the University of Cape Town and the clinic authorities granted approval for the study. The doctor at the clinic identified potential subjects. Once informed consent was obtained from patients, interviews were conducted. Following the first 10 interviews, responses were reviewed to adjust any ambiguous/ confusing questions. Responses were analyzed to create a profile of people with ALBP living in the community. All subjects were given an information sheet on the management of ALBP compiled by the researcher from evidence previously reviewed. Descriptive analyses identified activities commonly performed; subjects' perceptions about ALBP and treatment, and what subjects wanted to know about ALBP.

\section{Results}

The sample consisted of 50 subjects, $74 \%$ were female. The mean ages were 50.7 years (SD 14.0) and 54.1 years (SD 15.1) for males and females respectively. The mean BMI was 32 ( $\mathrm{SD}=5.3$ ) for males and $31.1(\mathrm{SD}=6.3)$ for females. Using the Center for Disease Control classifications $56 \%$ of subjects were obese or overweight (Center for Disease Control, 2005). Eight percent of subjects had spent 12 years at school - the 
full number of school years offered in South Africa. 34\% of subjects left school after 8-10 years while 58\% spent 7 years or less at school. Family income ranged from R1000 to R10000 per month. Forty six percent of subjects earned less than R1000 per month and 28\% between R1000 - R2000 per month. Categories used to describe occupation were obtained from the South African Department of Labour (Labour, 2007). Thirty three percent of subjects interviewed were Service and Sales Workers, 24\% worked in the Craft and Related Trades Category and $16 \%$ were Pensioners.

\section{Risk factors}

\section{Smoking}

Seventy eight percent currently were or had been smokers.

\section{House, garden and work activities}

Sweeping was the most common household activity performed by $94 \%$ of subjects, followed by mopping, 52\%, scrubbing $52 \%$ and vacuuming $44 \%$. Grocery shopping was the most common heavy load, carried by $42 \%$ of subjects. Carrying heavy wet washing was reported by $10 \%$ of subjects, this was especially difficult for those living in apartment blocks, as the washing lines were outside on the ground floor. Fifty-six percent of respondents worked in the garden doing activities such as sweeping, weeding, raking and planting. Twisting (72\%), bending (84\%), lifting $(62 \%)$ and awkward postures (70\%) were commonly used at work with all four postures being reported by over $60 \%$ of subjects. These postures were used for more than 7 hours a day by $70 \%$ of the respondents.

\section{Potential Sources of Stress}

Sixty percent of subjects were unable to meet their monthly expenses with their salary and over $50 \%$ reported financial problems. Twenty-two percent reported problems with their children and a few subjects referred to the increasing problem of drug addiction amoung young children in the Western Cape area of South Africa as reported by the Medical Research Council (Parry, 2004)

\section{Exercises and activity restriction}

Fifty two percent of subjects exercised by walking (perhaps by necessity), while $24 \%$ of subjects did not exercise and $10 \%$ reported doing their own exercises and stretches. Low back pain restricted many aspects of daily life in over $70 \%$ of subjects - exercise (48\%), housework $(52 \%)$ and work $(50 \%)$. Difficulty in dressing due to LBP was reported in over $60 \%$ of subjects.

\section{Information about LBP}

The majority of participants $(65 \%)$ expected the pain to recur and $40 \%$ did not anticipate complete recovery in the future. All 50 subjects wanted information on how the spine works, on lifting, exercise, pain management, correct sleep positions and how to cough and sneeze without exacerbating the LBP.

\section{Perception of Visit to Doctor}

Over $60 \%$ of subjects reported that the doctor had given them a solution but $20 \%$ percent wanted a referral for further advice or management. Examination and medication prescription were the most common stated expectations of the doctor. Advice (15\%) and education (5\%) were less expected, although desired interventions.

\section{Discussion}

\section{Introduction}

There are disadvantages to using a convenience sample, however respondents were similar in education and employment status to residents of other underresourced areas in Cape Town, as defined in a census of 2001 (City of Cape Town, 2001).Themajority had hadlimitedaccess to education (in 2001, 34\% had only primary school education or less, $47 \%$ had not completed high school). More respondents were not employed (60\% in 2001) and of those that were, all were in elementary occupations (33\% in 2001).

It is unlikely that the sample is representative of all LBP sufferers in the area as clinic-based samples are usually biased - those who have less pain may not attend and those who have severe pain may not be able to reach the clinic, particularly in a community where there are few private cars. In addition, people who have the financial resources/health insurance may choose to go to a doctor in the private sector or self-medicate. However the intention of the study was to investigate the needs of those who access the government health clinics. This sample is only representative of people with LBP in this community who seek care at a local clinic.

\section{Characteristics of the sample}

More women were represented in the sample. Another study using clinic-based samples in the Western Cape report a similar preponderance (Jelsma, 2004). As females apparently make greater use of public facilities and respond more readily to participation in surveys, the gender distribution might not necessarily be due to a greater incidence of LBP in females.

The level of education of this group of subjects was not high, with only one quarter achieving a school-leaving certificate. Studies have indicated conflicting results when looking at LBP and levels of education (Foppa and Noack, 1996; Takeuchi et al., 2004; Takeyachi et al., 2003).

A high percentage of the subjects were obese and there are some studies that have made a possible connection between obesity and LBP (Govender, 2004; Shiri et al., 2008).

Many of the subjects were smokers. Smokers with LBP have been reported to be hospitalized more often than nonsmokers for their LBP (Kaila-Kangas et al., 2003). A link between smoking and disc degeneration (Battie et al., 2004; Kaila-Kangas et al., 2003; Roughley, 2004) a possible precursor to LBP, has been suggested as chemicals inhaled during smoking may cause contraction of the capillary network in the spine reducing blood flow (and nutrient supply) to the disc increasing the risk of degeneration (Roughley, 2004; Urban et al., 2004).

\section{Physical Activities precipitating and exacerbating pain}

The second objective of this study was to establish activities precipitating and exacerbating pain. The MORGEN study in the Netherlands looked at physical load in different professions of 22,415 people and identified risk factors of: 
"lifting, twisting, pulling, pushing, bending" (Picavet and Schouten, 2000) similar postures/activities used in domestic work and other activities of daily living described in the current study. A Japanese study showed that more physically demanding occupations had a $35 \%$ higher incidence of LBP (Kaneda et al., 2001) and an interview study of 10,000 men in Canada showed "heavy work" to be a predictor of back pain (Kopec et al., 2004). In the USA, 568 patients seeking treatment for acute occupational LBP, found that those involved in more physical jobs more likely to have greater functional limitations (Shaw et al., 2005). Reduction of physical activity due to LBP in the current study was apparent with 50\% of subjects stopping work, housework and exercise. This was higher than the Canadian study mentioned above where $27 \%$ of all subjects took time off work for LBP (Gross et al., 2006). The Canadians may have had greater access to other forms of treatment.

\section{Psycho-social Influences}

Many subjects reported financial constraints - taking time off work for LBP could be stressful for these people if they did not get paid sick leave. A study in Japan highlights the problem of stress as it was found to be related to musculoskeletal complaints with LBP being one of the most common (Takeuchi et al., 2004). Subjects were also very worried about their LBP and did not expect to recover. This may not be unusual as in a telephone survey of 1200 subjects in Canada, (83\% who had had at least one episode of LBP) $50 \%$ of subjects thought that LBP "gets progressively worse, makes everything in life worse and eventually stops you from working"(Gross et al., 2006). These factors contribute to findings that many people with LBP also suffer from depression (Cecchi et al., 2006) and that people who suffer from both LBP and depression are also more likely to use more medication and experience higher levels of disability (Haggman et al., 2004; Takahashi et al., 2006).

\section{Determination of need}

Only a small percentage of subjects initially expressed the need for inter- vention other than medication but a high percentage agreed that they would like information on different aspects of back pain and back care concurring with results from the Back Home Study (Roberts et al., 2002a). The results of a study by (Burton et al., 1999) suggest people with LBP should be encouraged to become more confident in taking responsibility for their pain. Having more information might increase their confidence in their own capacities to manage the pain. Information is often the principal motivator for going to the doctor (Burton et al., 1999; Roberts et al., 2002a) and some research results suggest that patients be given "accurate and up-to-date information and advice about LBP" (Burton et al., 1999). It has been indicated that if not given information patients could be unsatisfied. The Burten et al study (1999) highlighted the main reason for patient dissatisfaction with medical care for LBP was the failure " to receive an adequate explanation of LBP".

The profile obtained from this study could be used to compile an information leaflet on LBP, advising patients on management of LBP, encouraging subjects to remain active at home and work with specific suggestions of how to reduce the risk of further LBP related to the environments in which these subjects lived. The issues of smoking and obesity could be broached.

The pamphlet that was already in use was published for a company producing anti-inflammatory drugs and although it was written by a physiotherapist it was mainly a list of exercises in picture form and advice about posture that were not necessarily appropriate for this community. The pamphlet given by the researcher contained advice but did not address any expressed needs of the community it was provided for as it was obviously written before the information was collected. Again, information used in other studies was written for communities in the countries being targeted such as the United States and United Kingdom.

\section{Limitations of the study}

Gathering applicable information was limited by the type of patients inter- viewed. It seemed that participants were not used to being involved in discussion with regard to their health conditions and found it hard to volunteer information until specifically asked. Furthermore, the choice of a clinic-based sample precluded inferences regarding prevalence of LBP in the area. If the questionnaire utilized was administered to a large community based sample, it would provide useful epidemiological data, to infer causal relationships and target the variables most implicated in LBP in future educational interventions.

\section{Conclusion}

A typical profile of people presenting with LBP in this resource poor community was identified showing a high prevalence of smoking, obesity and low levels of education. There were a high percentage of domestic and other manual workers in this community and the nature of their activities put them at risk for development and exacerbation of LBP.

The need for additional knowledge regarding the cause and prognosis of LBP was expressed and evident, as few people knew what to expect with regard to the likely outcome of their pain or how to deal with it. Subjects were also keen to have information about their spine and were interested in finding out how they themselves could deal with LBP. Development of an information leaflet to help dispel the pre-conceived ideas that apparently fuel distress and exacerbate LBP will be facilitated by the obtained profile of LBP patients in this community. Further exploration could reveal ways of presenting the information obtained in a way that might appeal/ be useful for this particular community.

The impact of LBP on the perceptions, physical and social functioning of the respondents was considerable and, particularly in a community with limited resources dependant on income from manual work, effective management of LBP should be a priority for the health authorities.

\section{Acknowledgements}

The South African Society of Physiotherapy and the Research Committee of the University of Cape Town for funding. 


\section{APPENDIX 1}

\section{Lifestyle Questionnaire:}
1) Apo
3 conser
2) Nowe
4) Wolpt
5) Marta Satas
a) Number of pers of behool
n) Oecugasen

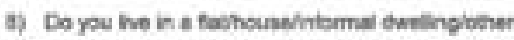
9) How far are the atces tom you home
90) Wonedy neomen of firmey
11) How mary people does sin upoent
52) Do you have ary atain at homo inate and ou
13) How many
14) How mary hours a night do you shes
15) What ind of aurbee do pou slibep of tonthard
69) How mavy hours of phyacal activily catside work do you do so mee.
57) What ine of aciovy
15i) Do you amekn
49) How many a der
20) Have you ever sonoand
21) For how mary your
2a) When did you ntoo
23) De you dink abonet
ad) What
25) How moch a wow

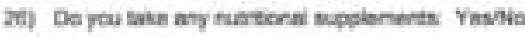
27) Do rou do any wok arownd the house?
o) Viciuming YeuNes
b) Hoppirg Yosivo
c) Smeeping Yesivo
ze) De rou make beds Yeanto
29) What kind of covers de your beste have
36) De rou do asy work in the gavdenhand Yastlo
31) What?
a) Do you na kemy eblects at home YesNo
3) Whas?
3) Do you for trings arsund the houat that in eny wer puta strain on your back Yeslio
35) Do pou cary heary lowos.
3e) Whan
37) No you currantly amployed YesNo
3e) How kng have yos oont this job?
9b) Whet work did you do telore?

40) How mary hours do you work per day

45) How many diga a net

42) How many deya holidey do you have a year

aj) Do you do that wot Youko

44) Cvertime Yesws

46) How mush coretime do pou do per woek

46) How many das have you taben off in sick leare in tha last yea?

47) How do you get to work centbuslaniwalk

48) How long som in touse

49) Does your work inctwe any of the tolowing powares:

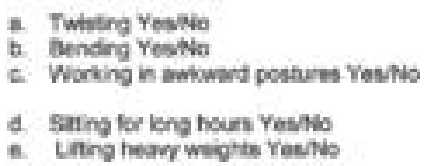

50) How many hours in a doy would you be using these poshras

51) In the last year have you

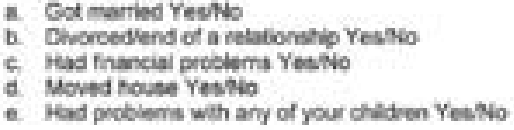

5a) Do you sleep wee at riget Yosave

53) Do you the your job Yea/lo

54) Ne you atie to eanly met your expenses woh your silary Yes/No
55) Are you the kind of perion that taks about your problems Yesavo

56) Da you have ary ceter haah prockems Yeswo

57) Do you foel you have a healty det Yeswo

58) What do you Eirk ia imeotane for a hathy det

s9] What do you firk causes bock pain

coj Why do you think you have bock pain

an What is the best way to deal wha back pain

a2) Can a dector help Yasive

(3) How?

s4) Do you krow what a Ptysictherapitt is Yes/lo

35) Do you know what a Phyecherapist soes Yes/ls

(a) What?

57) Could you die fom beck pain YeaNo

(6) Dess anyons in your tamly sutlor tom bask pain YesiNo

e9) Who?

70) Cen bock pein get botar wircot het Yasws

71) What is an $x$ ray

72) is an X-ray importart when you have bed pain YesiNo

73) Do tatiets helo back pain Yestio

74) Can amecise helo back pain Yes/va

75) Heve you had beck pain in the pent Yesllo

Te) for how many yoars? 


\section{APPENDIX 1}

\section{Lifestyle Questionnaire (Continued):}

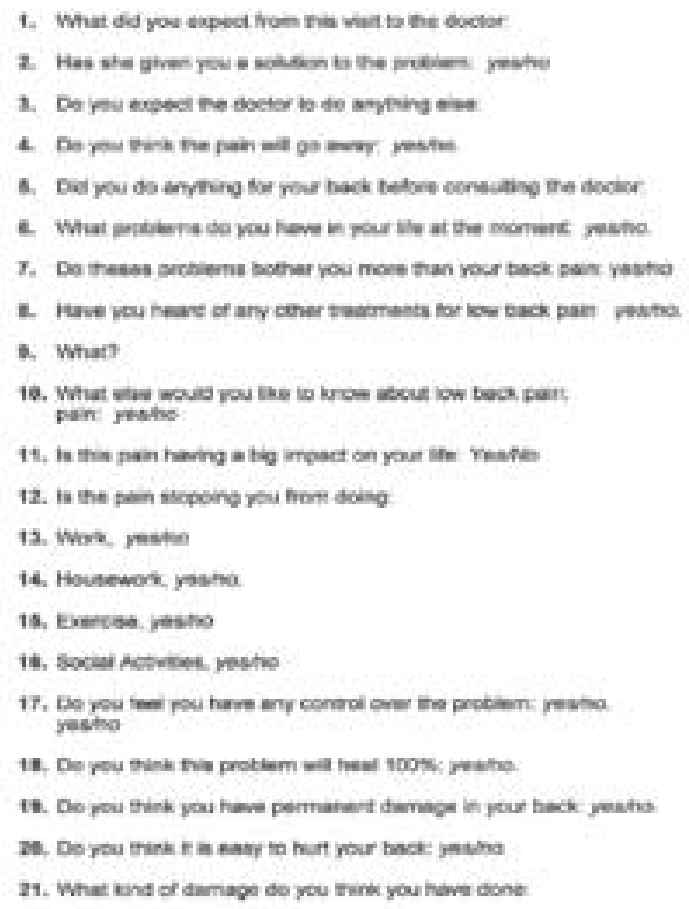

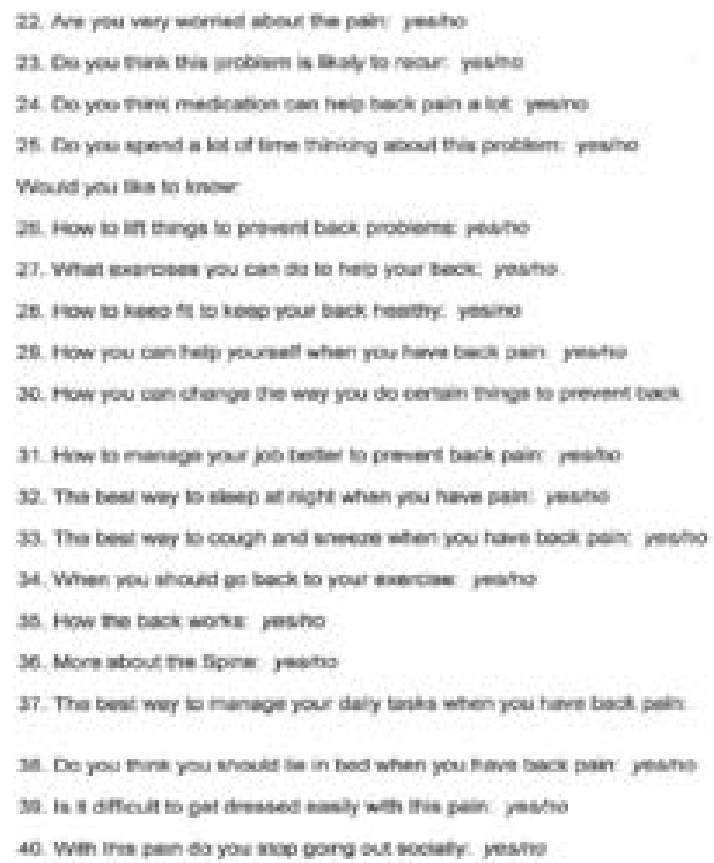

\section{Declaration of interest}

The authors report no conflicts of interest. The authors alone are responsible for the content and writing of the paper.

\section{References}

Battie MC, Videman T, Parent E. (2004) Lumbar disc degeneration: epidemiology and genetic influences. Spine 29:2679-2690.

Burton AK, Waddell G, Tillotson KM, Summerton N. (1999) Information and advice to patients with back pain can have a positive effect. A randomized controlled trial of a novel educational booklet in primary care. Spine 24: 2484-2491.

Cecchi F, Debolini P, Lova RM, Macchi C, Bandinelli S, Bartali B, Lauretani F, Benvenuti E, Hicks G, Ferrucci L. (2006) Epidemiology of back pain in a representative cohort of Italian persons 65 years of age and older: the InCHIANTI study. Spine 31:1149-1155.
Center for Disease Control. 2005. Body Mass Index. In.

Cherkin DC, Deyo RA, Street JH, Hunt M, Barlow W. (1996) Pitfalls of patient education. Limited success of a program for back pain in primary care. Spine 21:345-355.

City of Cape Town. 2001. 2001 Census. In.

Department of Health WC. 2006. Personal Communication. In.

Foppa I, Noack RH. (1996) The relation of self-reported back pain to psychosocial, behavioral, and healthrelated factors in a working population in Switzerland. Soc Sci Med 43: 1119-1126.

Goubert L, Crombez G, De Bourdeaudhuij I. (2004) Low back pain, disability and back pain myths in a community sample: prevalence and interrelationships. Eur J Pain 8:385-394.

Govender S. (2004) Low back pain in the nursing profession - a pilot study. SA Orthapaedic Journal May 2004:7-9.

Gross DP, Ferrari R, Russell AS, Battie MC, Schopflocher D, Hu RW,
Waddell G, Buchbinder R. (2006) A population-based survey of back pain beliefs in Canada. Spine 31:2142-2145.

Haggman S, Maher CG, Refshauge KM. (2004) Screening for symptoms of depression by physical therapists managing low back pain. Phys Ther 84:1157-1166.

Jelsma JME, Hughes, J, Tinise X, Darder M:. (2004) An investigation into the Health Related Quality of Life of individuals living with HIV who are receiving Highly Active Antiretroviral Therapy (HAART). Aids Care 17:579-588.

Jin K, Sorock GS, Courtney TK. (2004) Prevalence of low back pain in three occupational groups in Shanghai, People's Republic of China. J Safety Res 35:23-28.

Kaila-Kangas L, Leino-Arjas P, Riihimaki H, Luukkonen R, Kirjonen J. (2003) Smoking and overweight as predictors of hospitalization for back disorders. Spine 28:1860-1868.

Kaneda K, Shirai Y, Miyamoto M. (2001) An epidemiological study on 
occupational low back pain among people who work in construction. J Nippon Med Sch 68:310-317.

Kopec JA, Sayre EC, Esdaile JM. (2004) Predictors of back pain in a general population cohort. Spine 29: 70-77; discussion 77-78.

Korthals-de Bos I, van Tulder M, van Dieten H, Bouter L. (2004) Economic evaluations and randomized trials in spinal disorders: principles and methods. Spine 29:442-448.

Labour Do. 2007. Occupational Categories Form EEA10, Annexure 3 of the regulations to the Employment Equity Act 55 of 1998. In: Labour Department of the Government of South Africa.

Liddle SD, Baxter GD, Gracey JH. (2004) Exercise and chronic low back pain: what works? Pain 107:176-190.

Little P, Roberts L, Blowers H, Garwood J, Cantrell T, Langridge J, Chapman J. (2001) Should we give detailed advice and information booklets to patients with back pain? A randomized controlled factorial trial of a self-management booklet and doctor advice to take exercise for back pain. Spine 26:2065-2072.

Louw QA, Morris LD, GrimmerSomers K. (2007) The prevalence of low back pain in Africa: a systematic review. BMC Musculoskelet Disord 8:105.

Luo X, Pietrobon R, Sun SX, Liu GG, Hey L. (2004) Estimates and patterns of direct health care expenditures among individuals with back pain in the United States. Spine 29:79-86.

Lutz GK, Butzlaff M, Schultz-Venrath U. (2003) Looking back on back pain: trial and error of diagnoses in the 20th century. Spine 28:1899-1905.

Moffett JK, Torgerson D, Bell-Syer S, Jackson D, Llewlyn-Phillips H, Farrin A, Barber J. (1999) Randomised controlled trial of exercise for low back pain: clinical outcomes, costs, and preferences. Bmj 319:279-283.

Parker R, Jelsma J. (2010) The prevalence and functional impact of musculoskeletal conditions amongst clients of a primary health care facility in an under-resourced area of Cape Town. BMC Musculoskelet Disord 11:2.

Parry C. 2004. The need for a sciencebased approach to addressing substance abuse in the Western Cape. Medical Research Council, South Africa.

Picavet HS, Schouten JS. (2000) Physical load in daily life and low back problems in the general populationThe MORGEN study. Prev Med 31: 506-512.

Rivero-Arias O, Gray A, Frost H, Lamb SE, Stewart-Brown S. (2006) Cost-utility analysis of physiotherapy treatment compared with physiotherapy advice in low back pain. Spine 31: 1381-1387.

Roberts L, Little P, Chapman J, Cantrell T, Pickering R, Langridge J. (2002a) The back home trial: general practitioner-supported leaflets may change back pain behavior. Spine 27: 1821-1828.

Roberts L, Little P, Chapman J, Cantrell T, Pickering R, Langridge J. (2002b) General Practitioner-Supported Leaflets May Change Back Pain Behaviour. Spine 27:1821-1828.

Roughley PJ. (2004) Biology of intervertebral disc aging and degeneration: involvement of the extracellular matrix. Spine 29:2691-2699.

Santos-Eggimann B, Wietlisbach V, Rickenbach M, Paccaud F, Gutzwiller F. (2000) One-year prevalence of low back pain in two Swiss regions: estimates from the population participating in the 1992-1993 MONICA project. Spine 25:2473-2479.

Schenk RJ, Doran RL, Stachura JJ. (1996) Learning effects of a back education program. Spine 21:2183-2188; discussion 2189.

Shaw WS, Pransky G, Patterson W, Winters T. (2005) Early disability risk factors for low back pain assessed at outpatient occupational health clinics. Spine 30:572-580.

Shiri R, Solovieva S, HusgafvelPursiainen K, Taimela S, Saarikoski LA, Huupponen R, Viikari J, Raitakari OT, Viikari-Juntura E. (2008) The association between obesity and the prevalence of low back pain in young adults: the Cardiovascular Risk in Young Finns Study. Am J Epidemiol 167:1110-1119.

Takahashi N, Kikuchi S, Konno S, Morita S, Suzukamo Y, Green J, Fukuhara S. (2006) Discrepancy between disability and the severity of low back pain: demographic, psychologic, and employment-related factors. Spine 31:931-939; discussion 940.

Takeuchi T, Nakao M, Nishikitani M, Yano E. (2004) Stress perception and social indicators for low back, shoulder and joint pains in Japan: national surveys in 1995 and 2001. Tohoku J Exp Med 203:195-204.

Takeyachi Y, Konno S, Otani K, Yamauchi K, Takahashi I, Suzukamo Y, Kikuchi S. (2003) Correlation of low back pain with functional status, general health perception, social participation, subjective happiness, and patient satisfaction. Spine 28:1461-1466; discussion 1467.

The Royal College of General Practioners. 2009. Low Back Pain: early management of non-specific low back pain. In: National Collaborating Centre for Primary Care, UK.

Urban JP, Smith S, Fairbank JC. (2004) Nutrition of the intervertebral disc. Spine 29:2700-2709.

Walker BF, Muller R, Grant WD. (2004) Low back pain in Australian adults. health provider utilization and care seeking. J Manipulative Physiol Ther 27:327-335.

Woolf AD, Pfleger B. (2003) Burden of major musculoskeletal conditions. Bull World Health Organ 81:646-656. 